\title{
A Single-Institutional Study of Human Immunodeficiency Virus-Related Bladder Cancer
}

\section{Mengmeng Zhang ( $\sim$ zmm870604@ccmu.edu.cn)}

Capital Medical University Affiliated Beijing Youan Hospital https://orcid.org/0000-0001-7632-7702

\section{Yanyan Zhang}

Capital Medical University Affiliated Beijing Youan Hospital

\section{Zhiqiang Zhu}

Capital Medical University Affiliated Beijing Youan Hospital

\section{Yu Zhang}

Capital Medical University Affiliated Beijing Youan Hospital

\section{Research Article}

Keywords: Human immunodeficiency virus, Bladder cancer, Aggressive pathology, Outcomes

Posted Date: July 16th, 2021

DOl: https://doi.org/10.21203/rs.3.rs-705534/v1

License: (1) This work is licensed under a Creative Commons Attribution 4.0 International License. Read Full License 


\section{Abstract}

Purpose: We wished to investigate the clinical characteristics, treatments for tumor, pathology and outcomes of bladder cancer patients with HIV-infected.

Patients and methods: We identified 10 cases of bladder cancer with HIV-infected from 2015 to 2020 . We retrospectively investigated the clinical characteristics of the cases including demographic information, clinical presentation, TNM stage and so on. We investigated treatments for tumor, pathology, outcomes and HIV-relevant parameters during patients' hospitalization course as well.

Results: In our study, it was astonished to find that bladder cancer patients with HIV-infected were males at the median age of 51 years old, and no females were diagnosed on the contrary. Nine (90\%)patients presented with painless gross hematuria, while one patient with incidental findings on ultrasonic examination. Six $(60 \%)$ patients co-infected with another kind of infectious disease, four with syphilis, and two with HBV respectively. The median CD $4^{+}$T-lymphocyte cell count was 493/ul withthin 2 weeks prior to the diagnosis bladder cancer. Cystoscope examination manifested that the lesions were located in the trigonum of the bladder in four(40\%)patients. All patients underwent surgeries successfully, six underwent transurethral resection of bladder tumor(TURBT),two of whom relapsed once, and one underwent TURBT twice due to recurrence and then RC and urethrectomy because of urethral invasion. All non muscle-invasive bladder cancer(NMIBC)patients received intravesical chemotherapy with pirarubicin $30 \mathrm{mg}$ for at least half year conventionally, and only one patient occurred mild adverse reaction of irritative symptoms of bladder. Pathologic analysis documented that all patients(100\%) had transitional cell carcinoma(TCC). Tumor grade classification showed that three cases were identified with low grade TCC, and six cases with high grade or invasive TCC, two of whom occurred recurrence for once or twice respectively. One patient was identified with low grade TCC of primary tumor and high grade TCC of recurrent focal(Figure 2). Five cases (50\%) were ascertained as (NMIBC) with pT1NOM0, while the rest five patients(50\%) were muscle-invasive bladder cancer(MIBC) with at least pT2N0M0. During the median follow-up of 56 months (range from 5 months

to 68 months) six cases(five were MIBC patients )died due to distant metastases. No patients acceptted adjuvent immunotherapy mainly due to the role of PD- $1^{+} \mathrm{T}$ cells in HIV transcription in treated aviremic individuals, concerns of unknown adverse effects and economic factors.

Conclusions: It seemed like that bladder caner patients had higher tumor stage and more aggressive pathology. we did not find any evidence on the relationship between immunodeficiency and cancer progression because of relatively stable HIV status of this crew in our study. MIBC patients with HIV-infected really have worse outcomes, and more attention is warranted to pay to this special population in this situation when they present with hematuria extraordinarily.

\section{Introduction}

Human immunodeficiency virus(HIV) attacks body's immunal system by infecting dendritic cells and macrophages,causing deficits in T-cell function, and leading to obvious immunosuppression. HIV had elevated certain cancer risks due to the poor treatment response to HIV,such as Kaposi's sarcoma, non-Hodgkin lymphoma [NHL], and invasive cervical carcinoma we called acquired immune deficiency syndrome (AIDS)-defining cancers[1]. However the situation changed, HIV infection turns into a chronic disease because of the advent of highly active antiretroviral therapy (HAART) worldwide.Nowadays HIV-infected patients have a much longer life 
expectancy, and an increasement in the incidence of other non-AIDS-defining cancers is gradually noted along with improved life expectancy representing nearly one quarter to one third of all causes to death [2,3,4]. Bladder cancer is one kind of non-AIDS-defining cancers with a worldwide percentage of $3 \%$ of 19.3 million new cases in 185 countries in 2020 and ranks tenth among all 36 cancers[5], while few cases of bladder caner with HIVinfected have been reported.

The prior published cases refered to bladder caner with HIV-infected were mostly identified from the United States, Europe and Africa. To our knowledge,the first report on this unique population from Uganda manifested that the incidence of bladder cancer with the emergence of AIDS decreased[6]. On the contrary,a epidemiologic study used data from the HIV/AIDS Cancer Match Study to investigate urinary tract cancers among people with AIDS in the United States showed a decline of incidence of bladder cancer in the HIV population compared to general population with a standardized incidence ratio of 0.7[7]. In a French series involved $15 \mathrm{HIV}$-infected patients with bladder cancer indicated that HIV perhaps resulted in aggressive pathology and poor outcomes[8].A retrospective study of 11 cases from the United States showed HIV-positive patients with bladder cancer seemed like to present at a slightly younger age and with only mild immunosuppression and experience an expected course for their tumor[9].

In 2010, A cancer research in cohort of HIV-infected population in China identified 2 bladder cancer cases from 3554 patients showed a substantial increasement of incidence and poor outcomes of this population compared to general population with a standardized incidence ratio of 4.6 , which was the first study in China to estimate cancer incidence of various cancer sites among HIV-infected individuals[10]. However single studies of bladder caner with HIV-infected were still rare and inconclusive in terms of cancer incidence,cancer risks, pathology,outcomes and so on,especially in Asia.We retrospectively investigated 10 cases of bladder caner with HIV-infected, and attempted to learn clinical characters, treatment measures, pathology, outcomes,and HIVrelevant parameters,to preliminarily indicate if there was an obvious difference between HIV-infected and general population in those of above aspects.

\section{Patients And Methods}

The cases were screened from patients over a 5-year duration from 2015 to 2020 who accepted inpatient treatment at the Department of Urology, Beijing Youan hospital,Capital Medical University.We retrospectively analyzed their medical records,so as to collect patients' clinical characteristics including demographic information, clinical presentation and so on. We investigated treatments for tumor, pathology, outcomes and HIVrelevant parameters including CD4+ T-lymphocyte cell count, HIV viral load at diagnosis of RCC and treatment duration of HAART during patients' hospitalization course as well. Descriptive statistical analysis was utlized for the obtained data.

\section{Results}

\section{Clinical characteristics}

Ten patients diagnosed bladder caner with HIV infected were screened from inpatient records from 2015 to 2020 . The median age was 51 years old(range from 31 to 72).All patients were males, and no females were diagnosed on the contrary. Four patients occurred co-infection with HIV and syphilis, while two patients with HIV and HBV. 
Only one patient complicated with Type 2 Diabetes who had the history of Non-Hodgkin's lymphoma two years ago,while the remaining patients occurred no other chronic comorbidities including hypertension and

cardiovascular disease. Only one(10\%) patient had been a smoker for more than 10 years, and the remaining patients had no history of smoking by contrast.Nine (90\%)patients presented with painless gross hematuria, while one patient with incidental findings on ultrasonic examination. All patients underwent

cystoscope.Cystoscope examination manifested that the lesions were located in the trigonum of the bladder in four(40\%)patients. Three patients had tumor masses involving posterior bladder wall,left bladder wall,and right bladder wall respectively,and two patients involving vesical neck(Table 1). One patient occurred tumor filling the whole bladder and invading prostatic urethra(Fig. 1).

\section{Hiv-relevant Parameters}

All patients(100\%) regularly accepted HAART with a median duration of 36 months (range from 12 months to 120 months) prior to diagnosis of bladder cancer. Nine patients underwent viral load detected within 3 months of diagnosis of bladder cancer, five of whom had a viral load of target not detected (TND), three had a viral load of $<40$ copies/mL, and one had a viral load of 6008 copies $/ \mathrm{mL}$. The median CD4 ${ }^{+}$T-lymphocyte cell count was 493/ul withthin 2 weeks prior to the diagnosis of bladder cancer (range from 202 cells/ $\mu$ l to 759 cells/ $\mu$ l) (Table 1). A rapid mean decline of $46 \%$ of $C D 4^{+}$T-lymphocyte cell count was observed in four patients underwent T-cell subsets test withthin three days post to the surgery.

Table 1 Clinical characteristics and HIV-relevant parameters 


\begin{tabular}{|c|c|c|c|c|c|c|c|c|}
\hline Case & Gender & Age & Comorbidity & Presentation & $\begin{array}{l}\text { CD4count } \\
\text { (cells/ } / \mathrm{L} \text { ) }\end{array}$ & $\begin{array}{l}\text { Viral load } \\
\text { (copies/mL) }\end{array}$ & $\begin{array}{l}\text { HAART } \\
\text { duration } \\
\text { (months) }\end{array}$ & $\begin{array}{l}\text { Tumor } \\
\text { location }\end{array}$ \\
\hline 1 & Male & 51 & $\begin{array}{l}\text { Diabetes } \\
\text { NHL }\end{array}$ & Hematuria & 527 & $<40$ & 24 & Left wall \\
\hline 2 & Male & 72 & Syphilis & Hematuria & 202 & TND & 12 & $\begin{array}{l}\text { Bladder } \\
\text { neck }\end{array}$ \\
\hline 3 & Male & 50 & None & Hematuria & 459 & $<40$ & 12 & $\begin{array}{l}\text { Whole } \\
\text { bladder }\end{array}$ \\
\hline 4 & Male & 59 & Hepatitis B & Hematuria & 227 & TND & 96 & Trigonum \\
\hline 5 & Male & 31 & None & Hematuria & 759 & TND & 36 & $\begin{array}{l}\text { Right } \\
\text { wall }\end{array}$ \\
\hline 6 & Male & 66 & None & Hematuria & 535 & TND & 84 & $\begin{array}{l}\text { Posterior } \\
\text { wall }\end{array}$ \\
\hline 7 & Male & 47 & Hepatitis B & Hematuria & 293 & TND & 120 & Trigonum \\
\hline 8 & Male & 51 & Syphilis & Hematuria & 265 & $<40$ & 36 & Trigonum \\
\hline 9 & Male & 39 & Syphilis & Hematuria & 634 & 6008 & 24 & $\begin{array}{l}\text { Bladder } \\
\text { neck }\end{array}$ \\
\hline 10 & Male & 56 & Syphilis & $\begin{array}{l}\text { Incidental } \\
\text { finding }\end{array}$ & 558 & NT & 36 & Trigonum \\
\hline
\end{tabular}

\section{Pathology}

Pathologic analysis documented that all patients(100\%) had transitional cell carcinoma(TCC). Tumor grade classification showed that three cases were identified with low grade TCC, and six cases with high grade or invasive TCC, two of whom occurred recurrence for once and twice respectively. One patient was identified with low grade TCC of primary tumor and high grade TCC of recurrent focal(Fig. 2).Five cases(50\%) were ascertained as non muscle-invasive bladder cancer(NMIBC) with PT1NOM0, while the rest five patients(50\%) were muscleinvasive bladder cancer(MIBC) with at least PT2NOM0.Two MIBC cases invaded prostatic urethera and perivesical tissue(Table 2).

\section{Treatments and outcomes}

All patients accepted surgeries,three( $30 \%)$ underwent radical cystectomy $(\mathrm{RC})$ at the time of initial diagnosis,six(60\%)underwent transurethral resection of bladder tumor(TURBT), two of whom relapsed once, and one underwent TURBT twice due to recurrence and then RC and urethrectomy because of urethral invasion.All NMIBC patients received intravesical chemotherapy with pirarubicin $30 \mathrm{mg}$ for at least half year conventionally, and only one patient occurred mild adverse reaction of irritative symptoms of bladder. During the median follow-up of 56 months (range from 5 months to 68 months) six cases(five were MIBC patients)died due to distant metastases who refused adjuvent chemotherapy considering the side effects and severity of 
cancer,one died of liver metastasis eleven months after TURBT,one died of liver,bone,and rectum metastasis seven months after RC,two died of lung metastasis sixteen months and twenty months after RC respectively. The remaining cases who are NMIBC patients are still alive with the same follow-up plan utlizing urinalysis, cystoscope, ultrasonic examination, and CT scan as general patients(Table 2).

Table 2

Pathology, treatment, and outcomes

\begin{tabular}{|c|c|c|c|c|c|c|}
\hline Case & Surgery & TNM stage & $\begin{array}{l}\text { Grade } \\
\text { classification }\end{array}$ & $\begin{array}{l}\text { Follow-up duration } \\
\text { (months) }\end{array}$ & $\begin{array}{l}\text { Relapse } \\
\text { times }\end{array}$ & Outcomes \\
\hline 1 & $\begin{array}{l}\text { TURBT } \\
\text { TURBT }\end{array}$ & T1N0M0 T1N0M0 & Low High & 68 & 1 & Alive \\
\hline 2 & $\begin{array}{l}\text { TURBT } \\
\text { TURBT }\end{array}$ & T1N0M0 T1N0M0 & High High & 67 & 1 & Dead \\
\hline 3 & $\begin{array}{l}\text { TURBT } \\
\text { TURBT RC }\end{array}$ & $\begin{array}{l}\text { T1NOMO T1NOMO } \\
\text { T4NOMO }\end{array}$ & $\begin{array}{l}\text { High High } \\
\text { High }\end{array}$ & 57 & 2 & Dead \\
\hline 4 & $\mathrm{RC}$ & T2NOMO & High & 57 & None & Dead \\
\hline 5 & TURBT & T2NOMO & Low & 54 & None & Dead \\
\hline 6 & $\mathrm{RC}$ & T2NOMO & High & 54 & None & Dead \\
\hline 7 & $\mathrm{RC}$ & T3NOMO & High & 34 & None & Dead \\
\hline 8 & TURBT & T1N0M0 & High & 28 & None & Alive \\
\hline 9 & TURBT & T1N0M0 & Low & 14 & None & Alive \\
\hline 10 & TURBT & T1NOMO & Low & 5 & None & Alive \\
\hline
\end{tabular}

\section{Discussion}

We reviewed a series of ten bladder caner cases with HIV-infected in Beijing Youan Hospital, which is the largest HIV follow-up center in China.This literature is the largest published series of this crew in Asia at present.

Advanced age, male sex, and cigarette smoking were considered to be main risk factors contribute to the development of bladder cancer [11].The median onset age of bladder caner cases with HIV-infected in our study was 51 years old, and it was slightly younger than the published largest series of this crew at an meidan age of 55 and 56 years respectively [8,9],while the median age of diagnosis of baladder cancer had been demonstrated between 70 and 84 years in genneral population[11]. It was astonished that ten cases were all males casually, which strongly supported a male preponderance documented in published series of this crew $[8,9]$ and was in accordance with the general population proved by physicians[5,12]. A male preponderance might not only attribute to exposures and lifestyle of man, but also stasis of urine-containing carcinogens in old males with prostatic hyperplasia and urinary retention according to the former study[13,14]. We have insufficient proof that cigarette smoking was a risk factor of this crew,because only one smoker was found. 
Gross hematuria is the most common clinical presentation of bladder cancer leading to a risk of bladder cancer with $16.5 \%$ in general patients[15]. Almost every patient had gross hematuria prior to the diagnosis of bladder cancer treated in time in our study, however five patients were MIBC with at least PT2NOMO and six patients were dead withthin the follow-up duration. The former study indicated that the risk of bladder cancer was nearly $4 \%$ in patients with microscopic hematuria[15]. In view of this situation, we should pay more attention to microscopic hematuria when HIV-infected patients test urinalysis during regular follow-up of AIDS in order to enable to identify bladder cancer patients earlier. Cystoscopy utlized to evaluate the lower urinary tract is a critical screening method for patients who presented hematuria. Cystoscopy was used to learn about conditions of lesions in order to determine the most appropriate surgical plan.In our study cystoscopy showed the most common location of the lesions was trigonum of the bladder,whie the most common tumor location documented by a national corhot sdudy from United states including 4163 patients was the lateral wall[16].Moreover the sdudy showed that trigone tumors were associated with more aggressive tumor stages and worse overall survival[16], which was in line with our results. $\otimes$

We investigated patients' immunal status in terms of CD4 ${ }^{+} \mathrm{T}$ lymphocyte cell count and HIV viral load, which were well controlled due to regular HAART with a median duration of 36 months. For this reason we did not find any evidence on the relationship between immunodeficiency and cancer progression. We preliminarily detected a phenomenon that rapid mean decline of $46 \%$ of CD4+ T-lymphocyte cell count was found in four patients underwent T-cell subsets test withthin three days post to the surgery, which was never observed in the two largest previous studies in the United States and France[8,9]. We could not draw any conclusions on the this descreasing tendency because of lack of adequate data and tracking of the value.

Bladder cancer stems from the urothelial cells,which accounts for approximately $90 \%$ to $95 \%$ of urothelial cancer. Bladder cancer consisted of 75\% transitional cell carcinoma(TCC)and 25\% "variant" histology documented in the former study[17], while our study came up with an extreme proportion of 100\% supporting TCC preponderance in HIV-infected patients as well. Tumor grade classified into high grade,low grade,and papillary urothelial neoplasm of low malignant potential described as the 2004 WHO grading system[18]. NMIBC with pT1 stage represents approximately $75 \%$ of bladder cancer in general population refer to less aggressive feature. HIVinfected patients in our study was the high rate of MIBC with pT2 stage in $50 \%$ and high grade histology in $60 \%$, which was nearly the same as former study in this crew and much higher than the general population reported by physicians[8,19].Patients of bladder cancer are more likely to have aggressive pathological features with regard to bad outcomes in summary.

TURBT is the gold standard treatment for bladder cancer with T1 stage, that not only provides therapeutic benefit but also prognostic information to guide further management of NMIBC[20]. At least 50\% of general patients will have residual tumor or missed muscle-invasive tissue in TURBT specimens without muscle invasion, that's why bladder tumors are more likely to relapse[21]. A high recurrence rate of NMIBC has been estimated over $75 \%$ if untreated, and a meta-analysis of published results of randomized clinical trials showed a $39 \%$ decline of tumor relapse with intravesical chemotherapy at a median follow-up of 3.4 years[22].In our sudy cancer relapse was seen in 3 patients(50\% of T1-stage patients) who accepted regular intravesical chemotherapy of pirarubicin after TURBT,that demonstrated the efficacy of pirarubicin in this crew. Intravesical Bacille Calmette-Guérin (BCG) is the preferred treatment for high-risk NMIBC. Intravesical BCG relies on the activation of immunal cell subsets including $\mathrm{CD}^{+} \mathrm{T}$ lymphocytes as a method of immunotherapy, meanwhile there is a theoretical increased danger of disseminated infection acknowledging the immunodeficiency[23]. We did not recommend intravesical BCG for 
these reasons. However little efficacy experience had been shared,one HIV-infected patient of bladder cancer with T1 stage received intravesical BCG post to TURBT and had no infectious complications and relapse after BCG infusion in former study[9]. Another study refer to three renal transplant recipients with bladder cancer showed none developed systemic M. bovis infection after BCG infusion, who received prophylactic antituberculosis therapy meanwhile[24]. The results remind us that intravesical BCG can be tried with appropriate precautions.

Treatment for MIBC patients comprises neoadjuvant therapy followed by RC, pelvic lymph node dissection,urinary diversion, and adjuvent therapy when occurs distant metastases including chemotherapy and immunotherapy[25].In our sudy four patients underwent RC, pelvic lymph node dissection, and urinary diversion at the time of initial diagnosis without neoadjuvant chemotherapy because of consideration of increased immunodeficiency and tumor progression. To our surprise, MIBC patients in our series were all dead withthin 2 years due to aggressive pathological features,and the disease progressed much faster than we expected,while MIBC patients in general population is associated with less favorable prognosis with 5 -year survival $30 \%-50 \%$ [26].The gap of survival observed between the two population may partly caused by the use of neoadjuvant,because former study showed $15 \%$ increasement of survival with neoadjuvant chemotherapy compared to RC alone[27].

We have little experience to share on adjuvant chemotherapy, because patients refused to accept adjuvent chemotherapy maily considering extremely bad prognosis,uncertain efficacy and side effects. We did not recommend the use of immunotherapy as general population, due to the role of PD-1 ${ }^{+} \mathrm{T}$ cells in HIV transcription in treated aviremic individuals,concerns of unforeseen side effects and economic factors. However former studies in general population have proved that high mutational burden of bladder cancer makes it susceptible to immunotherapy, particularly with checkpoint inhibitors((PD-1/PD-L1 inhibitors).A recent study showed that no concerning findings were found in HIV-infected patients with advanced cancer treated with checkpoint inhibitors, while checkpoint inhibitors were more likely to have comparable efficacy,tolerable adverse effects, and stable HIV status[28]. In a prospective clinical study including one HIV-infected TCC patient indicated that checkpoint inhibitors had no negative effects on $\mathrm{CD} 4^{+} \mathrm{T}$ lymphocyte cell count and HIV viral load,but cancer response was not reported[29]. It is quitely regrettable that the study on checkpoint inhibitors in bladder cancer patients with HIV-infected was too rare to draw meaningful conclusions as clinical guidelines.

\section{Conclusions}

Bladder cancer patients with HIV-infected were similar to the general population in terms of demographic information and clinical presentation, while the onset age was much younger. It seemed like that bladder caner patients with HIV-infected had higher tumor stage and more aggressive pathology,and we did not find any evidence on the relationship between immunodeficiency and cancer progression because of relatively stable HIV status of this crew in our study.MIBC patients with HIV-infected really have worse outcomes,and more attention is warranted to pay to this special population in this situation when they present with hematuria extraordinarily. More studies are necessary to confirm the safety and efficacy of adjuvent chemotherapy and immunotherapy in bladder cancer patients with HIV-infected in order to eliminate concerns when make a decision.

\section{Declarations}


Acknowledgments

We would like to thank our collaborators in pathology and radiology department for their great efforts to the study.

\section{Authors' contributions}

Mengmeng Zhang contributed research design, data collection, statistic analysis ,and manuscript writing/ editing. Yanyan zhang contributed image analysis. Zhiqiang Zhu and Yu Zhang revised the manuscript. Hui Liu was responsible for pathological analysis.

\section{Funding}

No funding was received for this study

\section{Ethics approval and consent to participate}

The research was reviewed and approved by the Ethics Committee of Beijing Youan Hospital Capital Medical University. The Ethics Committee archive number is LL-2019-176-K, and the approval number is [2020]035.

All the participants provided informed consent.

\section{Consent for publication}

Written informed consent for publication was obtained from all participants.

\section{Availability of data and material}

All data generated or analyzed during this study are included in this published article.

\section{Competing interests}

The authors declare that they have no competing interests

\section{References}

1. Martín-Moreno A, Muñoz-Fernández MA. Dendritic Cells, the Double Agent in the War Against HIV-1. Front Immunol. 2019 Oct;23:10:2485.

2. Morlat P, Roussillon C, Henard S, Salmon D, Bonnet F, Cacoub P, Georget A, Aouba A, Rosenthal E, May T, Chauveau M, Diallo B, Costagliola D, Chene G. ANRS EN20 Mortalité 2010 Study Group. Causes of death among HIV-infected patients in France in 2010 (national survey): trends since 2000. AIDS. 2014 May 15;28(8):1181-91.

3. Pantanowitz L, Schlecht HP, Dezube BJ. The growing problem of non-AIDS-defining malignancies in HIV. Curr Opin Oncol. 2006 Sep;18(5):469-78.

4. Robbins HA, Pfeiffer RM, Shiels MS, Li J, Hall HI, Engels EA. Excess cancers among HIV-infected people in the United States. J Natl Cancer Inst. 2015 Feb 6;107(4):dju503. 
5. Sung H, Ferlay J, Siegel RL, Laversanne M, Soerjomataram I, Jemal A, Bray F. Global Cancer Statistics 2020: GLOBOCAN Estimates of Incidence and Mortality Worldwide for 36 Cancers in 185 Countries. CA Cancer J Clin. 2021 May;71(3):209-49.

6. Wabinga HR, Parkin DM, Wabwire-Mangen F, Mugerwa JW. Cancer in Kampala, Uganda, in 1989-91: changes in incidence in the era of AIDS. Int J Cancer. 1993 Apr;22(1):26-36. 54(.

7. Layman AB, Engels EA. Kidney and bladder cancers among people with AIDS in the United States. J Acquir Immune Defic Syndr. 2008 Jul 1;48(3):365-7.

8. Chawki S, Ploussard G, Montlahuc C, Verine J, Mongiat-Artus P, Desgrandchamps F, Molina JM. Bladder Cancer in HIV-infected Adults: An Emerging Issue? Case-Reports and Systematic Review. PLoS One. 2015 Dec 7;10(12):e0144237.

9. Gaughan EM, Dezube BJ, Bower M, Aboulafia DM, Bohac G, Cooley TP, Pantanowitz L. HIV-associated bladder cancer: a case series evaluating difficulties in diagnosis and management. BMC Urol. 2009 Aug;31:9:10.

10. Zhang YX, Gui XE, Zhong YH, Rong YP, Yan YJ. Cancer in cohort of HIV-infected population: prevalence and clinical characteristics. J Cancer Res Clin Oncol. 2011 Apr;137(4):609-14.

11. Lenis AT, Lec PM, Chamie K, Mshs MD. Bladder Cancer: A Review. JAMA. 2020 Nov;17(19):1980-91. 324(.

12. Richters A, Aben KKH, Kiemeney LALM. The global burden of urinary bladder cancer: an update. World J Urol. 2020 Aug;38(8):1895-904.

13. Babjuk M. Bladder Cancer in the Elderly. Eur Urol. 2018 Jan;73(1):51-2.

14. Wang Y, Chang Q, Li Y. Racial differences in Urinary Bladder Cancer in the United States. Sci Rep. 2018 Aug;21(1):12521. 8(.

15. Edwards TJ, Dickinson AJ, Natale S, Gosling J, McGrath JS. A prospective analysis of the diagnostic yield resulting from the attendance of 4020 patients at a protocol-driven haematuria clinic. BJU Int. 2006 Feb;97(2):301-5. discussion 305.

16. Weiner AB, Desai AS, Meeks JJ. Tumor Location May Predict Adverse Pathology and Survival Following Definitive Treatment for Bladder Cancer: A National Cohort Study. Eur Urol Oncol. 2019 May;2(3):304-10.

17. Lobo N, Shariat SF, Guo CC, Fernandez MI, Kassouf W, Choudhury A, Gao J, Williams SB, Galsky MD, Taylor JA 3rd, Roupret M, Kamat AM. What Is the Significance of Variant Histology in Urothelial Carcinoma? Eur Urol Focus. 2020 Jul 15;6(4):653-663.

18. Cheng L, MacLennan GT, Lopez-Beltran A. Histologic grading of urothelial carcinoma: a reappraisal. Hum Pathol. 2012 Dec;43(12):2097-108.

19. Kirkali Z, Chan T, Manoharan M, Algaba F, Busch C, Cheng L, Kiemeney L, Kriegmair M, Montironi R, Murphy WM, Sesterhenn IA, Tachibana M, Weider J. Bladder cancer: epidemiology, staging and grading, and diagnosis. Urology. 2005 Dec;66(6 Suppl 1):4-34.

20. Patel SG, Cohen A, Weiner AB, Steinberg GD. Intravesical therapy for bladder cancer. Expert Opin Pharmacother. 2015 Apr;16(6):889-901.

21. Herr HW. The value of a second transurethral resection in evaluating patients with bladder tumors. J Urol. 1999 Jul;162(1):74-6.

22. Sylvester RJ, Oosterlinck W, van der Meijden AP. A single immediate postoperative instillation of chemotherapy decreases the risk of recurrence in patients with stage Ta T1 bladder cancer: a meta-analysis 
of published results of randomized clinical trials. J Urol. 2004 Jun;171(6 Pt 1):2186-90. quiz 2435.

23. Redelman-Sidi G, Glickman MS, Bochner BH. The mechanism of action of BCG therapy for bladder cancer-a current perspective. Nat Rev Urol. 2014 Mar;11(3):153-62.

24. Palou J, Angerri O, Segarra J, Caparrós J, Guirado L, Diaz JM, Salvador-Bayarri J, Villavicencio-Mavrich H. Intravesical bacillus Calmette-Guèrin for the treatment of superficial bladder cancer in renal transplant patients. Transplantation. 2003 Nov 27;76(10):1514-6.

25. Chang SS, Bochner BH, Chou R, Dreicer R, Kamat AM, Lerner SP, Lotan Y, Meeks JJ, Michalski JM, Morgan TM, Quale DZ, Rosenberg JE, Zietman AL, Holzbeierlein JM. Treatment of Non-Metastatic Muscle-Invasive Bladder Cancer: AUA/ASCO/ASTRO/SUO Guideline. J Urol. 2017 Sep;198(3):552-9.

26. Shadpour P, Emami M, Haghdani S. A Comparison of the Progression and Recurrence Risk Index in NonMuscle-Invasive Bladder Tumors Detected by Narrow-Band Imaging Versus White Light Cystoscopy, Based on the EORTC Scoring System. Nephrourol Mon. 2016 Jan 9;8(1):e33240.

27. Grossman HB, Natale RB, Tangen CM, Speights VO, Vogelzang NJ, Trump DL, deVere White RW, Sarosdy MF, Wood DP Jr, Raghavan D, Crawford ED. Neoadjuvant chemotherapy plus cystectomy compared with cystectomy alone for locally advanced bladder cancer. N Engl J Med. 2003 Aug;28(9):859-66. 349(.

28. Banga R, Procopio FA, Noto A, Pollakis G, Cavassini M, Ohmiti K, Corpataux JM, de Leval L, Pantaleo G, Perreau M. PD-1(+) and follicular helper T cells are responsible for persistent HIV-1 transcription in treated aviremic individuals. Nat Med. 2016 Jul;22(7):754-61.

29. Cook MR, Kim C. Safety and Efficacy of Immune Checkpoint Inhibitor Therapy in Patients With HIV Infection and Advanced-Stage Cancer: A Systematic Review. JAMA Oncol. 2019 Jul 1;5(7):1049-1054.

\section{Figures}

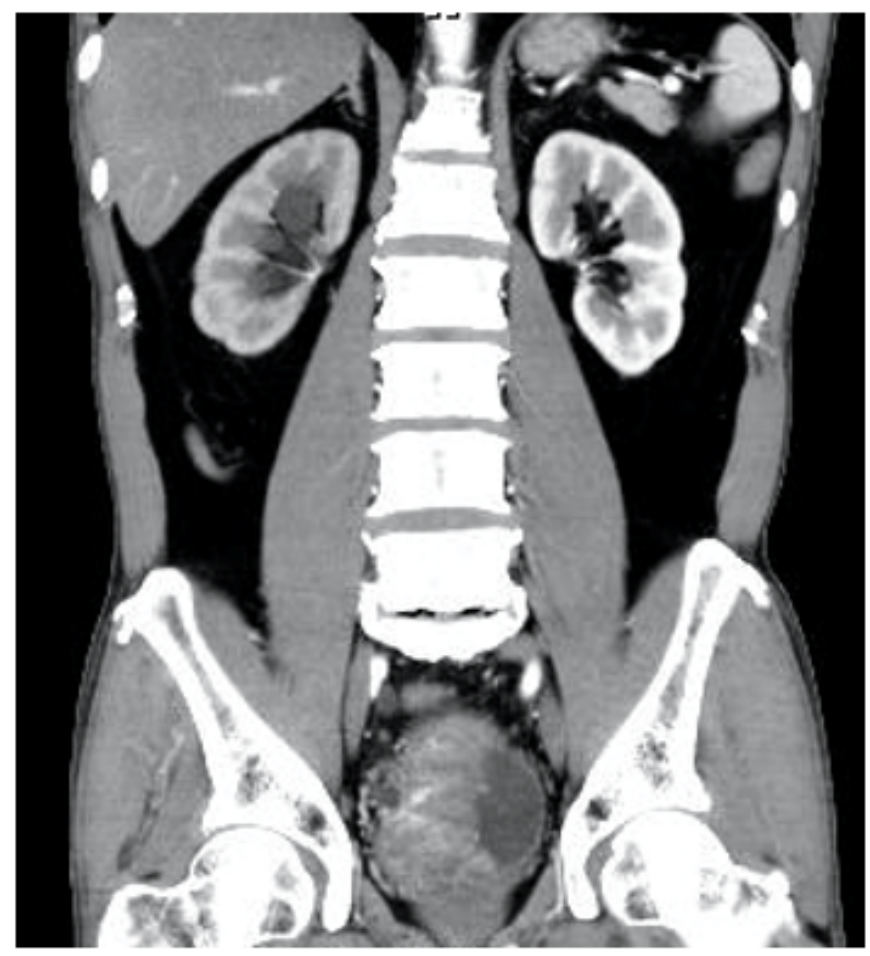

Figure 1 
CT scan of case 3:Large tumor filling the whole bladder and invading prostatic urethra

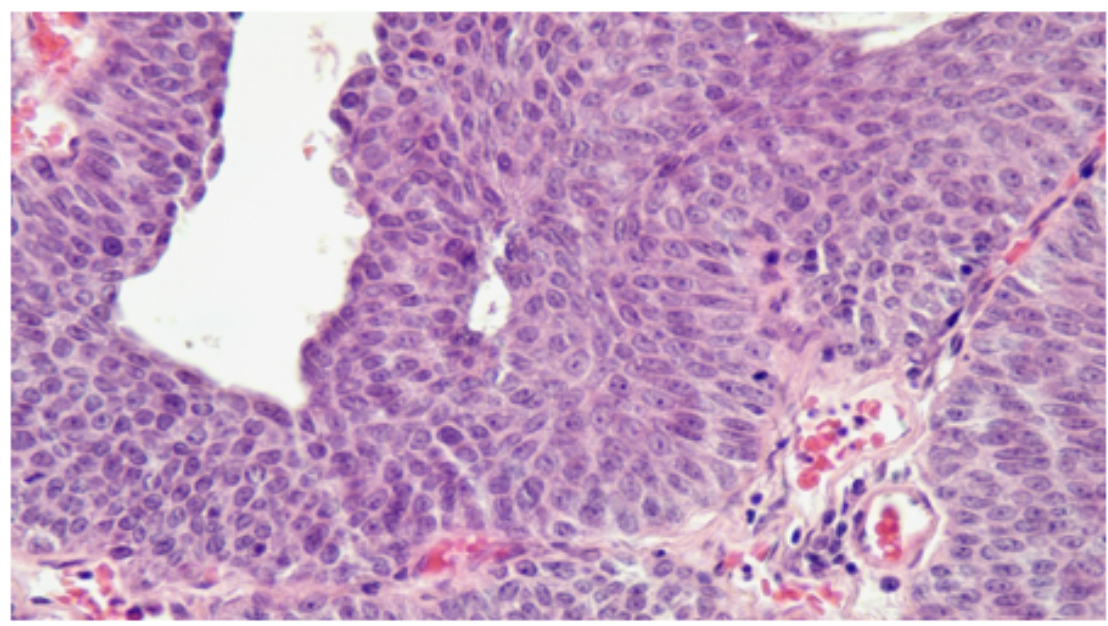

HEx400 Primary tumor with low grade

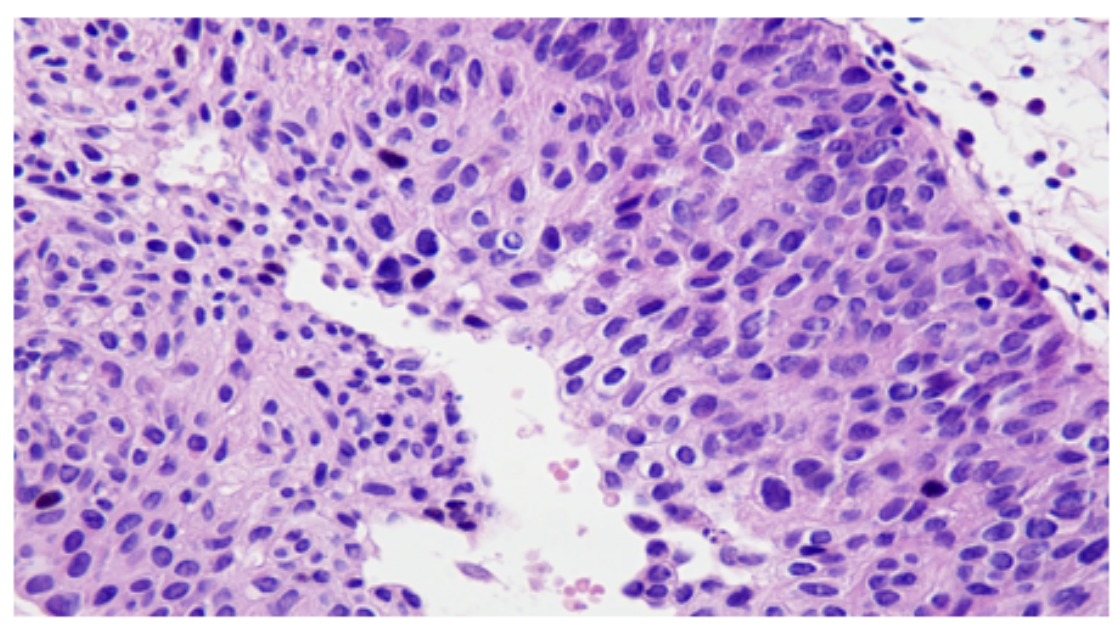

HE $\times 400$ Recurrent tumor with high grade

\section{Figure 2}

Case 1 with upgrade from low to high duo to tumor relapse 